\title{
Fluoride-Releasing Restorative Materials: The Effect of a Resinous Coat on Ion Release
}

\section{Utjecaj smolastog premaza na otpuštanje iona iz restaurativnih materijala koji otpuštaju fluoridne ione}

\author{
${ }^{1}$ Stomatološka poliklinika Zagreb, Perkovčeva ulica 3, Zagreb, Croatia \\ Stomatološka poliklinika Zagreb, Hrvatska \\ 2 Department of Endodontics and Restorative Dentistry, School of Dental Medicine, University of Zagreb, Gundulićeva 5, Zagreb, Croatia \\ Zavod za endodonciju i restaurativnu stomatologiju Stomatološkog fakulteta Sveučilišta u Zagrebu, Hrvatska \\ Katedra za farmakologiju Stomatološkog fakulteta Sveučilišta u Zagrebu, Hrvatska \\ ${ }^{3}$ Department of Pharmacology, School of Dental Medicine, University of Zagreb, Šalata 11, Zagreb, Croatia
}

\section{Abstract}

Objective: To determine the effect of two adhesive systems and a glass ionomer coating resin on fluoride release and concurrent $\mathrm{pH}$ changes over a period of 168 days. Material and methods: Four restorative materials were investigated: a giomer Beautiful II, an "alkasite" material Cention, a conventional composite Filtek Z250, and a glass ionomer cement Fuji IX Extra. Light-cured composite specimens were coated using G-aenial Bond and Clearfil Universal Bond Quick. Glass ionomer specimens were coated using GC Fuji Coat LC. Uncoated specimens were used as references. Quantitative fluoride release and $\mathrm{pH}$ changes were measured after 1 h, 24 h, 2 days, 7 days, 28 days, 84 days, and 168 days. Results: The cumulative fluoride release after 168 days increased for uncoated specimens in the following order: Filtek Z250 < Beautifil II < Cention < Fuji IX Extra. A comparatively lower fluoride release was measured for the composites coated with Clearfil Universal Bond Quick, with cumulative values after 168 days increasing in the following order: Filtek Z250 < Beautifil II < Cention. The composites coated with $\mathrm{G}$-aenial Bond showed lower fluoride release compared to the uncoated specimens, with cumulative values increasing in the following order: Filtek $Z 250<$ Beautifil II < Cention. The composites coated with $\mathrm{G}$-aenial Bond showed $\mathrm{pH}$ values in the acidic range (4.45.7) after $1 \mathrm{~h}$ and $24 \mathrm{~h}$. Conclusion: Fluoride release varied among the investigated restorative materials and depended on the use of dental adhesives and coatings. The $\mathrm{pH}$ of all materials, coating types and time points varied.
Received: September 14, 2020

Accepted: December 1, 2020

Address for correspondence Matej Par

University of Zagreb

School of Dental Medicine

Department of Endodontics and

Restorative Dentistry

Gundulićeva 5, HR-10 000 Zagreb

Phone: +38514802111

mpar@sfzg.hr

Key words

Dental Cements; Fluorides; HydrogenIon Concentration; Drug Liberation

\section{Introduction}

Glass ionomer cements (GICs), giomers, and composites are capable of releasing fluoride ions; therefore, they are used in restorative dental medicine for temporary and permanent fillings (1). Fluoride ions have been incorporated into dental materials. They have been shown to produce a remineralizing effect and reduce cariogenic potential by acting on the growth and metabolism of $S$. mutans (1-4).

The release of fluoride ions from dental materials depends on factors related to an individual material and factors related to oral environment. The characteristics of materials such as composition, filler content, powder/liquid ratio, mixing process, and surface exposed to the aqueous medium affect the release of fluoride ions. Environmental factors include the $\mathrm{pH}$ and composition of the immersion medium and application of a dental adhesive system or coat $(1,5-10)$.

Previous studies showed a negative effect of a dental adhesive system or coat on the quantity of released fluoride ions.

\section{Uvod}

Staklenoionomerni cementi (SIC), giomeri i kompoziti oslobađaju fluoridne ione i zato se primijenjuju u restaurativnoj dentalnoj medicini za privremene i trajne ispune (1). Pokazalo se da dodatak fluoridnih iona u zubne materijale remineralizacijski djeluje te smanjuje kariogeni potencijal bakterija što utječe na rast i metabolizam $S$. mutans $(1-4)$.

Otpuštanje fluoridnih iona iz dentalnih materijala ovisi o čimbenicima koji su vezani za svaki materijal te onima povezanima s oralnim okolišem. Karakteristike materijala kao što su sastav, sadržaj punila, omjer prah - tekućina, postupak miješanja i površina izložena vodenom mediju utječu na otpuštanje fluoridnih iona. Čimbenici okoliša uključuju pH i sastav imerzijskog medija te primjenu dentinskoga adhezijskog sustava ili premaza za staklenoionomerne cemente $(1,5-10)$.

$\mathrm{U}$ ranijim ispitivanjima autori su istaknuli negativan učinak dentinskih adhezijskih sustava ili premaza na ukupnu količinu otpuštenih fluoridnih iona jer se smatra da tvore hi- 
This has been attributed to the adhesive system or coat forming a hydrophobic barrier and thereby diminishing the diffusion of fluoride ions. This effect was more pronounced in resin composites than in GICs, which depended on type of the adhesive system or coat $(7,11-13)$.

Apart from the well-known classes of restorative materials that are capable of releasing fluoride ions (GICs and giomers), a novel "alkasite" restorative material has recently been introduced to the dental market. This bioactive material is capable of releasing remineralizing calcium and fluoride ions and can also neutralize acid by releasing $\mathrm{OH}^{-}$ions. It is compositionally similar to the group of composite materials and is designed to be used with or without an adhesive system, depending on the operator's preferences $(14,15)$.

The effect of contemporary universal adhesives on fluoride release from remineralizing resin composite materials has not been investigated up to date. Therefore, the aim of this study was to compare fluoride release from specimens of restorative materials that were either coated or uncoated with a resinous layer of an adhesive system (for composite materials) and coat (for a GIC). Additionally, the effects of a resinous layer on the $\mathrm{pH}$ changes of the immersion medium were investigated. The first null hypothesis was that there would be no difference in fluoride ion release and $\mathrm{pH}$ changes between coated and uncoated specimens. The second null hypothesis was that the release of fluoride ions and $\mathrm{pH}$ changes of the immersion medium did not differ among the investigated restorative materials.

\section{Material and methods}

Restorative materials, adhesive systems, and a glass ionomer coat investigated in this study are presented in Table 1. Six specimens were prepared for each experimental group (n =6).

Specimens of the composite materials were prepared using cylindrical Teflon molds with a diameter of $6 \mathrm{~mm}$ and a height of $2 \mathrm{~mm}$. The molds were placed on a polyethylene terephthalate (PET) foil, filled with uncured material and covered with another layer of PET foil (16). The excess material was removed and specimens were polymerized using an LED curing unit (Bluephase G2, Ivoclar Vivadent, Schaan, Liechtenstein) with a nominal intensity of $1200 \mathrm{~mW} / \mathrm{cm}^{2}$ for $20 \mathrm{~s}$ on each side. Specimens of the GIC were cast into the mold described above, covered with PET films, and left to set for 6 min according to manufacturer's instructions (17). To ensure that the specimens were completely surrounded by an aqueous medium, a plastic thread incorporated within each specimen was used to hang the specimens from the cap of the vial.

The schematic overview of the study design is presented in Figure 1. Each sample was immersed separately in a plastic vial containing $5 \mathrm{ml}$ of deionized water at $37^{\circ} \mathrm{C}$ and evaluated after $0,1,2,7,28,84$, and 168 days. At each time interval, the specimens were removed from the immersion medium, placed in $5 \mathrm{ml}$ of new deionized water, and stored in the incubator at $37^{\circ} \mathrm{C}$ until the next time point. The $\mathrm{pH}$ of the immersion medium was measured using the $\mathrm{pH}$ meter $\mathrm{MP}$ 220 (Mettler Toledo, Columbus, Ohio) and the InLab Ex- drofobnu barijeru i time umanjuju difuziju fluoridnih iona. Učinak je bio izraženiji u smolastim kompozitima negoli u staklenoionomernim cementima te je ovisio o vrsti adhezijskog sustava ili premaza $(7,11-13)$.

Uz dosad poznate restaurativne materijale koji mogu otpuštati fluoridne ione (SIC i giomeri), na stomatološkom tržištu nedavno je predstavljen i jedan novi. Taj bioaktivni materijal otpušta remineralizirajuće ione kalcija i fluorida, a također može neutralizirati kiselinu otpuštanjem $\mathrm{OH}^{-}$iona. Sastavom je sličan skupini kompozitnih materijala i namijenjen je za upotrebu $s$ dentinskim adhezijskim sustavom ili bez njega, ovisno o željama operatera $(14,15)$.

Utjecaj suvremenih univerzalnih dentinskih adhezijskih sustava na otpuštanje fluoridnih iona iz remineralizirajućih kompozitnih materijala do danas nije istražen. Zato je cilj ove studije bio usporediti otpuštanje fluoridnih iona iz nepremazanih uzoraka i uzoraka restaurativnih materijala tretiranih smolastim slojem adhezijskog sustava (za kompozitne materijale) i premazom (za SIC-e). Također su istraživani učinci smolastoga sloja na promjene $\mathrm{pH}$ vrijednosti imerzijskog medija. Prva nulta hipoteza bila je da neće biti razlike u otpuštanju fluoridnih iona i promjeni $\mathrm{pH}$ između premazanih i nepremazanih uzoraka. Druga nulta hipoteza glasila je da se otpuštanje fluoridnih iona i promjene $\mathrm{pH}$ imerzijskog medija ne razlikuju među istraživanim restaurativnim materijalima.

\section{Materijali i postupci}

Restaurativni materijali, dentinski adhezijski sustavi i staklenoionomerni premaz istraživani u ovoj studiji navedeni su u tablici 1 . Za svaku skupinu bilo je pripremljeno šest uzoraka $(\mathrm{n}=6)$.

Uzorci kompozitnih materijala pripremljeni su s pomoću cilindričnih teflonskih kalupa promjera $6 \mathrm{~mm}$ i visine $2 \mathrm{~mm}$. Kalupi su postavljeni na polietilen-tereftalatnu foliju (PET), napunjeni materijalom i prekriveni drugim slojem PET folije (16). Višak materijala je uklonjen, a uzorci su polimerizirani LED (engl. light emitting diode) polimerizacijskom svjetiljkom Bluephase G2 (Ivoclar Vivadent, Schaan, Lihtenštajn) nominalnog intenziteta $1200 \mathrm{~m} \mathrm{~W} / \mathrm{cm}^{2}$ u trajanju od $20 \mathrm{se}$ kunda sa svake strane. Uzorci SIC-a stavljeni su u opisani kalup, prekriveni PET folijama i ostavljeni šest minuta da se stvrdnu, prema uputama proizvođača (17). Kako bi se osiguralo da su uzorci potpuno okruženi vodenim medijem, korišten je plastični konac inkorporiran u svaki uzorak, a s pomoću kojega su uzorci visjeli s čepa bočice.

Shematski prikaz dizajna studije nalazi se na slici 1 . Svaki uzorak bio je zasebno uronjen u plastičnu bočicu koja je sadržavala $5 \mathrm{~mL}$ deionizirane vode na temperaturi od $37^{\circ} \mathrm{C}$ i ispitivan nakon 0, 1, 2, 7, 28, 84 i 168 dana. Pri svakom vremenskom intervalu uzorci su uklonjeni iz imerzijskog sredstva, zatim stavljeni u $5 \mathrm{~mL}$ nove deionizirane vode i pohranjeni u inkubator na $37^{\circ} \mathrm{C}$ do sljedeće vremenske točke. $\mathrm{pH}$ vrijednost imerzijskog sredstva mjerila se $\mathrm{pH}$ metrom MP 220 (Mettler Toledo, Columbus, Ohio, SAD) i elektrodom InLab Expert Pro pH (Mettler Toledo, Columbus, Ohio, SAD). 
Table 1 Materials used in this study

Tablica 1. Materijali korišteni u istraživanju

\begin{tabular}{|c|c|c|c|c|}
\hline $\begin{array}{l}\text { Material class } \bullet \\
\text { Vrsta materijala }\end{array}$ & $\begin{array}{l}\text { Commercial name } \\
\text { (abbreviation) } \bullet \\
\text { Komercijalni naziv } \\
\text { (kratica) }\end{array}$ & Composition • Sastav & $\begin{array}{c}\text { Manufacturer • } \\
\text { Proizvodač }\end{array}$ & $\begin{array}{l}\text { Shade/LOT No. } \\
\text { Nijansa/LOT broj }\end{array}$ \\
\hline Giomer & Beautifil II (BF) & $\begin{array}{l}\text { S-PRG (surface pre-reacted glass ionomer) } \\
\text { Nano fillers } 83.3 \mathrm{wt} \% \bullet \text { Nano punila } 83,3 \text { wt } \%\end{array}$ & $\begin{array}{l}\text { Shofu Dental } \\
\text { GmbH, Ratingen, } \\
\text { Germany } \bullet \text { Njemačka } \\
\end{array}$ & A2/051829 \\
\hline Alkasite $\bullet$ Alkasit & Cention $(\mathrm{CN})$ & $\begin{array}{l}\text { Filler: calcium fluorosilicate glass, Ba-Al silicate glass, Ca-Ba-Al } \\
\text { fluorosilicate glass, Ytterbium trifluoride, Isofiller • Punila: } \\
\text { kalcijevo fluorosilikatno staklo, Ba-Al silikatno staklo, Ca-Ba-Al } \\
\text { fluorosilikatno staklo, iterbijev trifluorid, Isofiller } \\
\text { Monomers: urethane dimethacrylate UDMA, Tricyclodecan- } \\
\text { dimethanol dimethacrylate DCP, Aromatic-aliphatic-UDMA, } \\
\text { Polyethylene glycol } 400 \text { dimethacrylate PEG-400 DMA } \\
\text { - Monomeri: uretan-dimetakrilat UDMA, Triciklodekan- } \\
\text { dimetanol dimetakrilat DCP, aromatski-alifatski-UDMA, } \\
\text { Polietilen-glikol } 400 \text { dimetakrilat PEG-400 DMA } \\
\text { Initiator system: hydroperoxide, Ivocerin and acyl phosphine } \\
\text { oxide • Inicijatorski sustav: hidroperoksid, Ivocerin i acil-fosfin } \\
\text { oksid }\end{array}$ & $\begin{array}{l}\text { Ivoclar Vivadent, } \\
\text { Schaan, Liechtenstein } \\
\text { - Lihtenštajn }\end{array}$ & A2/XL7102 \\
\hline $\begin{array}{l}\text { Glass ionomer } \\
\text { Stakleni ionomer }\end{array}$ & Fuji IX Extra (FUJ) & $\begin{array}{l}\text { Liquid: } 5-10 \% \text { polybasic carboxylic acid } \bullet \text { Tekućina: } 5-10 \% \\
\text { polibazična karboksilna kiselina } \\
\text { Powder: glass, oxide } \bullet \text { Prašak: staklo, oksidi }\end{array}$ & $\begin{array}{l}\text { GC Europe, Leuven, } \\
\text { Belgium • Belgija }\end{array}$ & A3/1801171 \\
\hline $\begin{array}{l}\text { Conventional } \\
\text { composite } \\
\text { Konvencionalni } \\
\text { kompozit }\end{array}$ & Filtek Z250 (FIL) & $\begin{array}{l}\text { Matrix: Bisphenol A diglycidyl ether dimethacrylate (BIS- } \\
\text { GMA) and triethylene glycol dimethacrylate (TEGDMA), } \\
\text { UDMA • Matrica: Bisfenol A diglicidil dimetakrilat (BIS- } \\
\text { GMA) i trietilen-glikol dimetakrilat (TEGDMA), UDMA } \\
\text { Filler: zirconia and silica particles } 78.5 \mathrm{wt} \%, 60 \% \text { vol. • Punilo: } \\
\text { čestice cirkonija i silicijeva dioksida } 78,5 \mathrm{wt} \%, 60 \% \text { vol. }\end{array}$ & $\begin{array}{l}\text { 3M Deutschland } \\
\text { GmbH, Neuss, } \\
\text { Germany } \bullet \text { Njemačka }\end{array}$ & A2/N984652 \\
\hline $\begin{array}{l}\text { Universal adhesive } \\
\text { Univerzalni } \\
\text { adhezivni sustav }\end{array}$ & G-aenial Bond (GB) & $\begin{array}{l}\text { acetone } 25-50 \% \bullet \text { aceton } 25-50 \% \\
\text { dimethacrylate } 10-20 \% \bullet \text { dimetakrilat } 10-20 \% \\
\text { phosphoric acid ester monomer } 5-10 \% \bullet \text { monomer estera } \\
\text { fosforne kiseline } 5-10 \% \\
\text { dimethacrylate component } 1-5 \% \bullet \text { dimetakrilatna komponenta } \\
1-5 \% \\
\text { photoinitiator } 1-5 \% \bullet \text { fotoinicijator } 1-5 \% \\
\text { butylated hydroxytoluene }(\mathrm{BHT})<0.5 \% \bullet \text { butilirani } \\
\text { hidroksitoluen }(\mathrm{BHT})<0,5 \%\end{array}$ & $\begin{array}{l}\text { GC Europe, Leuven, } \\
\text { Belgium • Belgija }\end{array}$ & 1811281 \\
\hline $\begin{array}{l}\text { Universal fluoride- } \\
\text { releasing adhesive } \\
\text { Univerzalni } \\
\text { adhezivni sustav koji } \\
\text { otpušta fluoride }\end{array}$ & $\begin{array}{l}\text { Clearfil Universal } \\
\text { Bond Quick (CB) }\end{array}$ & $\begin{array}{l}\text { BIS-GMA 10-25\%, ethanol 10-25\%, 2-hydroxyethyl } \\
\text { methacrylate 2.5-10\%, 10-Methacryloyloxydecyl dihydrogen } \\
\text { phosphate, hydrophilic amide monomers, colloidal silica, } \\
\text { silane coupling agent, sodium fluoride, dl-Camphorquinone, } \\
\text { water • BIS-GMA } 10 \text { - } 25 \% \text {, etanol } 10 \text { - } 25 \% \text {, 2-hidroksietil } \\
\text { metakrilat 2,5-10\%, 10-metakriloiloksidecil dihidrogen-fosfat, } \\
\text { hidrofilni amidni monomeri, koloidni silicijev dioksid, silansko } \\
\text { vezno sredstvo, natrijev fluorid, dl-kamforkinon, voda }\end{array}$ & $\begin{array}{l}\text { Kuraray Europe, } \\
\text { Hattersheim am } \\
\text { Main, Germany } \\
\text { - Hattersheim na } \\
\text { Majni, Njemačka }\end{array}$ & 3L0108 \\
\hline $\begin{array}{l}\text { Glass ionomer coat } \bullet \\
\text { Staklenoionomerni } \\
\text { premaz }\end{array}$ & $\begin{array}{l}\text { GC Fuji Coat LC } \\
\text { (FC) }\end{array}$ & $\begin{array}{l}\text { methyl methacrylate }(\mathrm{MMA}) 25-50 \% \bullet \text { metil-metakrilat } \\
(\mathrm{MMA}) 25-50 \% \\
\text { photoinitiator } 1-5 \% \bullet \text { fotoinicijator } 1-5 \% \\
\text { butylated hydroxytoluene }(\mathrm{BHT})<1 \% \bullet \text { butilirani } \\
\text { hidroksitoluen }(\mathrm{BHT})<1 \%\end{array}$ & $\begin{array}{l}\text { GC Europe, Leuven, } \\
\text { Belgium • Belgija }\end{array}$ & 1804021 \\
\hline
\end{tabular}

\begin{tabular}{|c|c|c|c|c|c|c|c|c|c|c|}
\hline $\begin{array}{l}\mathrm{CN} 1 \\
\mathrm{n}=6\end{array}$ & $\begin{array}{l}B \text { BF } 1 \\
n=6\end{array}$ & $\begin{array}{l}\text { FIL } 1 \\
n=6\end{array}$ & $\begin{array}{l}\mathrm{CN} 2 \\
\mathrm{n}=6\end{array}$ & $\begin{array}{l}\mathrm{BF} 2 \\
\mathrm{n}=6\end{array}$ & $\begin{array}{r}\text { FIL } 2 \\
n=6\end{array}$ & $\begin{array}{l}\mathrm{CN} 3 \\
\mathrm{n}=6\end{array}$ & $\begin{array}{l}\mathrm{BF} 3 \\
\mathrm{n}=6\end{array}$ & $\begin{aligned} \text { FIL } 3 \\
n=6\end{aligned}$ & $\begin{array}{l}\mathrm{FUJ} 1 \\
\mathrm{n}=6\end{array}$ & $\begin{array}{c}\mathrm{FUJ} 2 \\
\mathrm{n}=6\end{array}$ \\
\hline 1 & 1 & 7 & 7 & 8 & 7 & 7 & 7 & 7 & \multicolumn{2}{|l|}{$\nabla$} \\
\hline \multicolumn{3}{|c|}{ light cured 20 s every side } & \multicolumn{3}{|c|}{$\begin{array}{l}\text { light cured } 20 \text { s every side, coated with } \\
\text { CB, light cured } 10 \mathrm{~s}\end{array}$} & \multicolumn{3}{|c|}{$\begin{array}{l}\text { light cured } 20 \mathrm{~s} \text { every side, coated with } \\
\text { GB, light cured } 10 \mathrm{~s}\end{array}$} & $\begin{array}{l}\text { left for } 6 \text { min } \\
\text { according to } \\
\text { manufacturer }\end{array}$ & \begin{tabular}{|} 
left for 6 min according \\
to manufacturer, coated \\
with $\mathrm{FC}$, light cured for \\
$10 \mathrm{~s}$
\end{tabular} \\
\hline \multicolumn{3}{|c|}{$\downarrow$} & & 7 & & \multicolumn{3}{|c|}{ 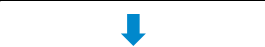 } & 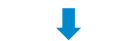 & 1 \\
\hline \multicolumn{11}{|c|}{ storage in $5 \mathrm{ml}$ of deionized water at $37^{\circ} \mathrm{C}$} \\
\hline
\end{tabular}

Figure 1 Schematic representation of the study design.

Slika 1. Shematski prikaz dizajna studije 
pert Pro $\mathrm{pH}$ electrode (Mettler Toledo, Columbus, Ohio). Prior to the $\mathrm{pH}$ measurement, the electrode was calibrated using standard buffer solutions at $\mathrm{pH}=4$ and $\mathrm{pH}=7$.

A volume of $4.5 \mathrm{ml}$ of the medium and $0.5 \mathrm{ml}$ of TISAB III buffer (Total Ionic Strength Adjustment Buffer, Thermo Fisher Scientific, Chelmsford, USA) were placed in a new beaker to determine the fluoride ions concentration. Quantitative fluoride ions release was measured using a standard ion-selective electrode Orion 9609BNWP (Thermo Fisher Scientific, Massachusetts, USA), ISO 19448: 2018. Before measurements, the ion-selective electrode was calibrated using a series of standards of known concentration in a range of $10^{-5}-10^{-2} \mathrm{~mol} / \mathrm{L} \mathrm{F}^{-}$.

The fluid samples were placed on a $\mathrm{RH}$ magnetic stirrer (IKA-Werke GmbH \& Co. KG, Staufen, Germany), which was set at $500 \mathrm{rpm}$ without heating. A sensor was placed inside the fluid sample, which rotated at the indicated speed during the measurement. An ion-selective electrode was connected to an Expandable Ion Analyzer EA 940 (Orion Research, Beverly, USA) from which the values were read. An average of 3 readings was calculated for each sample.

Normality of distribution was verified using the Shapiro Wilk's test, and equality of variances was checked using the Levene's test. Mean values of fluoride release and $\mathrm{pH}$ changes of the immersion medium were compared among the combinations of materials and resinous coatings using a one-way ANOVA with Tukey post-hoc adjustment. Mean values of fluoride release and $\mathrm{pH}$ changes of the immersion medium for each combination of materials and resinous coatings were compared among different measurement times using repeated-measures ANOVA with Bonferroni post-hoc adjustment. For all analyses, the overall level of significance was set at 0.05 . Statistical analysis was performed in SPSS 20 (IBM, Armonk, NY, USA).

\section{Results}

\section{Fluoride release}

Mean concentrations of released fluoride ions from uncoated specimens are presented in Figure 2. All uncoated groups showed a statistically significant increase in released fluoride ions over time in the following order: $\mathrm{BF}<\mathrm{CN}<$ FUJ. When comparing cumulative values after 168 days, FUJ demonstrated 3 times higher values than $\mathrm{CN}$, and 35 times higher values than $\mathrm{BF}$.

The effect of coating systems on fluoride release is shown in Table 2. The coating of composite specimens with adhesive systems led to a statistically significant decrease in the amount of released fluoride ions. Materials treated with GB released more fluoride ions than materials treated with $\mathrm{CB}$. FIL released fluoride ions only when fluoride-releasing adhesive CB was applied. Both FUJ groups showed a statistically significant increase in released fluoride ions over time, whereas uncoated specimens reached 30 times higher values compared to the specimens coated with FC.
Prije mjerenja $\mathrm{pH}$, elektroda je kalibrirana s pomoću standardnih puferskih otopina $\mathrm{pH}=4 \mathrm{i} \mathrm{pH}=7$.

Volumen od $4,5 \mathrm{~mL}$ tekućine i $0,5 \mathrm{~mL}$ pufera TISAB III (Total Ionic Strength Adjustment Buffer, Thermo Fisher Scientific, Chelmsford, SAD) stavljen je u novu čašicu za određivanje koncentracije fluoridnih iona. Kvantitativna količina otpuštenih fluoridnih iona mjerena je standardnom metodom ionski selektivnom elektrodom Orion 9609BNWP (Thermo Fisher Scientific, Massachusetts, SAD) propisanom normom ISO 19448:2018. Ionski selektivna elektroda se prije mjerenja baždarila standardnom metodom $s$ pomoću razrijeđenih komercijalnih standarda koncentracija u rasponu od $10^{-5}$ do $10^{-2} \mathrm{~mol} / \mathrm{L} \mathrm{F}^{-}$.

Pri mjerenju se uzorak tekućine nalazio na digitalnoj magnetskoj miješalici RH digital (IKA-Werke GmbH \& Co. KG, Staufen, Njemačka) koja je bila podešena na $500 \mathrm{rpm}$ (engl. revolutions per minute), bez grijanja miješalice. $U$ uzorak tekućine uronjen je senzor koji se tijekom mjerenja vrtio navedenom brzinom. Ionski selektivna elektroda bila je spojena na čitač Expandable IonAnalyzer EA 940 (Orion Research, Beverly, SAD) s kojega su se oćitavale vrijednosti. Za svaki uzorak tekućine očitale su se tri vrijednosti te izračunao njihov prosjek.

Normalnost distribucije rezultata provjerena je Shapiro-Wilksovim testom, a jednakost varijanci Leveneovim testom. Prosječne vrijednosti otpuštanja fluoridnih iona i promjene $\mathrm{pH}$ vrijednosti imerzijskog sredstva uspoređivane su među kombinacijama materijala i smolastih premaza korištenjem jednosmjerne ANOVA-e s Tukeyjevom post-hoc korekcijom. Prosječne vrijednosti otpuštanja fluoridnih iona i promjene $\mathrm{pH}$ imerzijskog sredstva za svaku kombinaciju materijala i smolastih premaza uspoređivane su između različitih vremenskih intervala korištenjem ponovljenih mjerenja ANOVA-e $s$ Bonferronijevom post-hoc korekcijom. Za sve analize je razina značajnosti bila postavljena na 0,05 . Statistička analiza provedena je u SPSS 20 programu (IBM, Armonk, NY, SAD).

\section{Rezultati}

\section{Otpuštanje fluoridnih iona}

Srednje vrijednosti koncentracija otpuštenih fluoridnih iona iz restaurativnih materijala bez premaza prikazane su na slici 2. Svi restaurativni materijali bez premaza pokazali su statistički značajan porast otpuštenih fluoridnih iona tijekom vremena sljedećim redoslijedom: $\mathrm{BF}<\mathrm{CN}<\mathrm{FUJ}$. Uspoređujući kumulativne vrijednosti nakon 168 dana, FUJ je pokazao tri puta veće vrijednosti od $\mathrm{CN}$-a i 35 puta veće od BF-a.

Učinak premaza na otpuštanje fluoridnih iona prikazan je u tablici 2. Premazivanje kompozitnih uzoraka dentinskim adhezijskim sustavima rezultiralo je statistički značajnim smanjenjem količine otpuštenih fluoridnih iona. Materijali tretirani GB-om otpustili su više fluoridnih iona od onih tretiranih CB-om. FIL je otpustio fluoridne ione samo kada je tretiran dentinskim adhezijskim sustavom CB. Obje FUJ skupine pokazale su statistički značajan porast otpuštenih fluoridnih iona tijekom vremena te su nepremazani uzorci dosegnuli 30 puta veće vrijednosti u usporedbi $s$ uzorcima premazanima FC-om. 


\begin{tabular}{|c|c|c|c|c|c|c|c|c|c|c|c|}
\hline $\begin{array}{l}\text { Table } 2 \\
\text { Tablica } 2 .\end{array}$ & $\begin{array}{l}\text { Fluoride io } \\
\text { materials s } \\
\text { Values are } \\
\text { Otpuštanje } \\
\text { podskupin } \\
\text { točke). Vrij }\end{array}$ & $\begin{array}{l}\text { pubroups } \\
\text { presented } \\
\text { fluoridnih } \\
\text { a materijala } \\
\text { ednosti su u }\end{array}$ & $\begin{array}{l}\text { th or with } \\
\text { ppm. Star } \\
\text { na iz prem } \\
\text { s premazo } \\
\text { ppm. Stan }\end{array}$ & $\begin{array}{l}\text { dard deviatio } \\
\text { azanih i nepre } \\
\text { n i bez prema } \\
\text { dardne devija }\end{array}$ & $\begin{array}{l}\text { ercase lette } \\
\text { ns are prese } \\
\text { iza). Mala sl } \\
\text { cije prikazan }\end{array}$ & $\begin{array}{l}\text { ted in pare } \\
\text { raka. Velik } \\
\text { va označav } \\
\text { e su u zagr }\end{array}$ & $\begin{array}{l}\text { tistically hor } \\
\text { theses. } \\
\text { slova označ } \\
\text { ju statističk } \\
\text { lama. }\end{array}$ & $\begin{array}{l}\text { mogeneous } \\
\text { čavaju statis } \\
\text { ki homogene }\end{array}$ & $\begin{array}{l}\text { laterials su } \\
\text { čki homoge } \\
\text { odskupine }\end{array}$ & $\begin{array}{l}\text { bgroups (tim } \\
\text { ene skupine } \\
\text { materijala ( }\end{array}$ & $\begin{array}{l}\text { vithin } \\
\text { ee points). } \\
\text { unutar } \\
\text { vremenske }\end{array}$ \\
\hline \multirow[b]{2}{*}{$\begin{array}{c}\text { Time } \\
(\text { days) } \\
\text { Vrijeme } \\
(\text { dani) }\end{array}$} & \multicolumn{3}{|c|}{ FILTEK Z250 } & \multicolumn{3}{|c|}{ BEAUTIFIL II } & \multicolumn{3}{|c|}{ CENTION } & \multicolumn{2}{|c|}{ FUJI IX EXTRA } \\
\hline & $\begin{array}{c}\text { Uncoated • } \\
\text { Bez } \\
\text { premaza }\end{array}$ & $\begin{array}{c}\text { Clearfil } \\
\text { Universal } \\
\text { Bond } \\
\text { Quick }\end{array}$ & $\begin{array}{c}\text { G-aenial } \\
\text { Bond }\end{array}$ & $\begin{array}{c}\text { Uncoated • } \\
\text { Bez } \\
\text { premaza }\end{array}$ & $\begin{array}{l}\text { Clearfil } \\
\text { Universal } \\
\text { Bond } \\
\text { Quick }\end{array}$ & $\begin{array}{c}\text { G-aenial } \\
\text { Bond }\end{array}$ & $\begin{array}{c}\text { Uncoated • } \\
\text { Bez } \\
\text { premaza }\end{array}$ & $\begin{array}{c}\text { Clearfil } \\
\text { Universal } \\
\text { Bond } \\
\text { Quick }\end{array}$ & $\begin{array}{c}\text { G-aenial } \\
\text { Bond }\end{array}$ & $\begin{array}{c}\text { Uncoated • } \\
\text { Bez } \\
\text { premaza }\end{array}$ & $\begin{array}{c}\text { GC Fuji } \\
\text { COAT LC }\end{array}$ \\
\hline 0 & 0 & $0 \mathrm{~A}$ & 0 & $\begin{array}{c}0.05 \\
(0.03) \mathrm{Aa} \\
\end{array}$ & $\begin{array}{c}0.026 \\
(0.02) \mathrm{Aab} \\
\end{array}$ & $\begin{array}{c}0.01 \\
(0.01) \mathrm{Ab} \\
\end{array}$ & $\begin{array}{c}0.08 \\
(0.02) \mathrm{Aa} \\
\end{array}$ & $\begin{array}{c}0.004 \\
(0.001) \mathrm{Ab} \\
\end{array}$ & $\begin{array}{c}0.005 \\
(0.002) \mathrm{Ab} \\
\end{array}$ & $\begin{array}{c}2.95(0.5) \\
\mathrm{A}\end{array}$ & $\begin{array}{c}0.18 \\
(0.06) \mathrm{A} \\
\end{array}$ \\
\hline 1 & 0 & $0 \mathrm{~A}$ & 0 & $\begin{array}{c}0.11 \\
(0.05) \mathrm{Aa}\end{array}$ & $\begin{array}{c}0.026 \\
(0.02) \mathrm{Ab}\end{array}$ & $\begin{array}{c}0.013 \\
(0.01) \mathrm{Ab}\end{array}$ & $\begin{array}{c}4.22 \\
(0.44) \mathrm{Ba}\end{array}$ & $\begin{array}{c}0.057 \\
(0.02) \mathrm{Ab}\end{array}$ & $\begin{array}{c}0.386 \\
(0.2) \mathrm{Ab} \\
\end{array}$ & $\begin{array}{c}7.95 \\
(0.89) \mathrm{B} \\
\end{array}$ & $\begin{array}{c}0.26(0.1) \\
\mathrm{A}\end{array}$ \\
\hline 2 & 0 & $0 \mathrm{~A}$ & 0 & $\begin{array}{c}0.14 \\
(0.06) \mathrm{Aa}\end{array}$ & $\begin{array}{c}0.026 \\
(0.02) \mathrm{Ab}\end{array}$ & $\begin{array}{c}0.013 \\
(0.05) \mathrm{Ab}\end{array}$ & $\begin{array}{c}7.15 \\
(0.64) \mathrm{Ca} \\
\end{array}$ & $\begin{array}{c}0.071 \\
(0.02) \mathrm{ABb} \\
\end{array}$ & $\begin{array}{c}0.462 \\
(0.22) \mathrm{Ab}\end{array}$ & $\begin{array}{c}9.94 \\
(0.84) \mathrm{C} \\
\end{array}$ & $\begin{array}{c}0.18 \\
(0.12) \mathrm{A}\end{array}$ \\
\hline 7 & 0 & $\begin{array}{c}0.0000833 \\
\mathrm{~A}\end{array}$ & 0 & $\begin{array}{c}0.22 \\
(0.07) \mathrm{Aa}\end{array}$ & $\begin{array}{c}0.025 \\
(0.02) \mathrm{Ab}\end{array}$ & $\begin{array}{c}0.016 \\
(0.04) \mathrm{Ab}\end{array}$ & $\begin{array}{c}8.93 \\
(0.75) \mathrm{Da}\end{array}$ & $\begin{array}{c}0.08(0.03) \\
\mathrm{ABCb}\end{array}$ & $\begin{array}{c}0.91 \\
(0.33) \mathrm{Ac}\end{array}$ & $\begin{array}{c}14.5 \\
(0.56) \mathrm{D}\end{array}$ & $\begin{array}{c}0.61 \\
(0.23) \mathrm{AB}\end{array}$ \\
\hline 28 & 0 & $\begin{array}{c}0.000695 \\
\text { B }\end{array}$ & 0 & $\begin{array}{c}0.6(0.16) \\
\mathrm{Ba}\end{array}$ & $\begin{array}{c}0.043 \\
(0.01) \mathrm{Ab}\end{array}$ & $\begin{array}{c}0.087 \\
(0.01) \mathrm{Ab}\end{array}$ & $\begin{array}{c}10.12 \\
(0.99) \\
\mathrm{DEa}\end{array}$ & $\begin{array}{c}0.23(0.05) \\
\mathrm{BCb}\end{array}$ & $\begin{array}{c}2.669 \\
(0.72) \mathrm{Bc}\end{array}$ & $\begin{array}{l}22.49 \\
(1.16) \mathrm{E}\end{array}$ & $\begin{array}{c}0.97 \\
(0.33) \mathrm{BC}\end{array}$ \\
\hline 84 & 0 & $\begin{array}{c}0.0007667 \\
B\end{array}$ & 0 & $\begin{array}{c}1.01 \\
(0.26) \mathrm{Ca}\end{array}$ & $\begin{array}{c}0.08 \\
(0.03) \mathrm{Bb}\end{array}$ & $\begin{array}{c}0.322 \\
(0.07) \mathrm{Bc}\end{array}$ & $\begin{array}{c}10.8 \\
(1.06) \mathrm{Ea}\end{array}$ & $\begin{array}{c}0.24 \\
(0.05) \mathrm{Cb}\end{array}$ & $\begin{array}{c}3.088 \\
(0.69) \mathrm{Bc}\end{array}$ & $\begin{array}{c}45.7 \\
(2.12) \mathrm{F} \\
\end{array}$ & $\begin{array}{c}1.18 \\
(0.42) \mathrm{C} \\
\end{array}$ \\
\hline 168 & 0 & $\begin{array}{c}0.0007667 \\
B\end{array}$ & 0 & $\begin{array}{c}2.19(0.4) \\
\mathrm{Da}\end{array}$ & $\begin{array}{c}0.08 \\
(0.03) \mathrm{Bb}\end{array}$ & $\begin{array}{c}1.77 \\
(0.17) \mathrm{Bc}\end{array}$ & $\begin{array}{c}12.75 \\
(1.07) \mathrm{Fa}\end{array}$ & $\begin{array}{c}0.80 \\
(0.23) \mathrm{Db}\end{array}$ & $\begin{array}{c}5.072 \\
(0.99) \mathrm{Cc}\end{array}$ & $\begin{array}{l}55.49 \\
(3) \mathrm{G}\end{array}$ & $\begin{array}{c}1.85(0.5) \\
D\end{array}$ \\
\hline
\end{tabular}

\begin{tabular}{|c|c|c|c|c|c|c|c|c|c|c|c|}
\hline \multirow[b]{2}{*}{$\begin{array}{c}\text { Time } \\
(\text { days) } \\
\text { Vrijeme } \\
(\text { dani) }\end{array}$} & \multicolumn{3}{|c|}{ FILTEK Z250 } & \multicolumn{3}{|c|}{ BEAUTIFIL II } & \multicolumn{3}{|c|}{ CENTION } & \multicolumn{2}{|c|}{ FUJI IX EXTRA } \\
\hline & $\begin{array}{c}\text { Uncoated • } \\
\text { Bez } \\
\text { premaza }\end{array}$ & $\begin{array}{l}\text { Clearfil } \\
\text { Universal } \\
\text { Bond } \\
\text { Quick }\end{array}$ & $\begin{array}{c}\text { G-aenial } \\
\text { Bond }\end{array}$ & $\begin{array}{c}\text { Uncoated • } \\
\text { Bez } \\
\text { premaza }\end{array}$ & $\begin{array}{l}\text { Clearfil } \\
\text { Universal } \\
\text { Bond } \\
\text { Quick }\end{array}$ & $\begin{array}{c}\text { G-aenial } \\
\text { Bond }\end{array}$ & $\begin{array}{c}\text { Uncoated • } \\
\text { Bez } \\
\text { premaza }\end{array}$ & $\begin{array}{l}\text { Clearfil } \\
\text { Universal } \\
\text { Bond } \\
\text { Quick }\end{array}$ & $\begin{array}{c}\text { G-aenial } \\
\text { Bond }\end{array}$ & $\begin{array}{c}\text { Uncoated • } \\
\text { Bez } \\
\text { premaza }\end{array}$ & $\begin{array}{c}\text { GC Fuji } \\
\text { COAT LC }\end{array}$ \\
\hline 0 & $\begin{array}{c}6.16 \\
(0.08) \mathrm{Aa}\end{array}$ & $\begin{array}{c}6.41(0.2) \\
\mathrm{Ab}\end{array}$ & $\begin{array}{c}4.42 \\
(0.08) \mathrm{Ac}\end{array}$ & $\begin{array}{c}7.27 \\
(0.16) \mathrm{Aa}\end{array}$ & $\begin{array}{c}6.64 \\
(0.33) \mathrm{Ab}\end{array}$ & $\begin{array}{c}4.75 \\
(0.11) \mathrm{Ac}\end{array}$ & $\begin{array}{c}6.83(0.11) \\
\mathrm{ABCa}\end{array}$ & $\begin{array}{l}7(0.2) \\
\mathrm{ABCa}\end{array}$ & $\begin{array}{c}4.53 \\
(0.16) \mathrm{Ab}\end{array}$ & $\begin{array}{c}6.47 \\
(0.27) \mathrm{A}\end{array}$ & $\begin{array}{c}6.42 \\
(0.08) \mathrm{A}\end{array}$ \\
\hline 1 & $\begin{array}{c}6.26 \\
(0.04) \mathrm{Aa}\end{array}$ & $\begin{array}{c}7.63 \\
(0.32) \mathrm{Cb}\end{array}$ & $\begin{array}{c}5.39 \\
(0.74) \mathrm{Bc}\end{array}$ & $\begin{array}{c}6.53 \\
(0.06) \mathrm{Ba}\end{array}$ & $\begin{array}{c}6.61 \\
(0.14) \mathrm{Aa}\end{array}$ & $\begin{array}{c}5.67 \\
(0.21) \mathrm{Bb}\end{array}$ & $\begin{array}{c}6.99(0.2) \\
\mathrm{Ca}\end{array}$ & $\begin{array}{c}6.52 \\
(0.19) \mathrm{Ab}\end{array}$ & $\begin{array}{c}5.73 \\
(0.38) \mathrm{Bc}\end{array}$ & $\begin{array}{c}6.81 \\
(0.33) \mathrm{AB}\end{array}$ & $\begin{array}{c}6.89 \\
(0.19) \mathrm{B}\end{array}$ \\
\hline 2 & $\begin{array}{c}7.5(0.32) \\
\mathrm{Da}\end{array}$ & $\begin{array}{c}7.5(0.4) \\
\mathrm{Ca}\end{array}$ & $\begin{array}{c}6.89 \\
(0.23) \mathrm{Cb}\end{array}$ & $\begin{array}{c}6.57 \\
(0.24) \mathrm{Ba}\end{array}$ & $\begin{array}{c}6.58 \\
(0.09) \mathrm{Aa}\end{array}$ & $\begin{array}{c}6.9(0.15) \\
\mathrm{CDb}\end{array}$ & $\begin{array}{c}6.61 \\
(0.15) \mathrm{Aa}\end{array}$ & $\begin{array}{c}6.92 \\
(0.51) \mathrm{Aba}\end{array}$ & $\begin{array}{c}6.79 \\
(0.25) \mathrm{Ca}\end{array}$ & $\begin{array}{c}7.11(0.2) \\
\text { B }\end{array}$ & $\begin{array}{c}6.96 \\
(0.22) \mathrm{B}\end{array}$ \\
\hline 7 & $\begin{array}{c}6.96 \\
(0.21) \mathrm{Ca}\end{array}$ & $\begin{array}{c}6.8(0.15) \\
\text { ABab }\end{array}$ & $\begin{array}{c}6.64 \\
(0.23) \mathrm{Cb} \\
\end{array}$ & $\begin{array}{c}6.99(0.2) \\
\mathrm{Aa}\end{array}$ & $\begin{array}{c}6.9(0.13) \\
\mathrm{ABa}\end{array}$ & $\begin{array}{c}7.44 \\
(0.27) \mathrm{Db} \\
\end{array}$ & $\begin{array}{c}6.87(0.26) \\
\mathrm{ABCa}\end{array}$ & $\begin{array}{c}7.55(0.25) \\
\mathrm{CDb}\end{array}$ & $\begin{array}{c}7.19(0.22) \\
\mathrm{Cab}\end{array}$ & $\begin{array}{c}6.76(0.1) \\
\mathrm{AB}\end{array}$ & $\begin{array}{c}7.64 \\
(0.29) \mathrm{C} \\
\end{array}$ \\
\hline 28 & $\begin{array}{c}6.96 \\
(0.09) \mathrm{Ca}\end{array}$ & $\begin{array}{c}6.49 \\
(0.11) \mathrm{Ab}\end{array}$ & $\begin{array}{c}6.4(0.09) \\
\mathrm{Cb}\end{array}$ & $\begin{array}{c}7.49 \\
(0.18) \mathrm{Ca}\end{array}$ & $\begin{array}{c}7.03(0.12) \\
\text { BCb }\end{array}$ & $\begin{array}{c}7.48 \\
(0.35) \mathrm{Da}\end{array}$ & $\begin{array}{c}6.68(0.19) \\
\mathrm{ABa}\end{array}$ & $\begin{array}{c}7.23(0.33) \\
\text { BCDa }\end{array}$ & $\begin{array}{c}6.85 \\
(0.58) \mathrm{Ca}\end{array}$ & $\begin{array}{c}6.57 \\
(0.16) \mathrm{A}\end{array}$ & $\begin{array}{c}7.79 \\
(0.22) \mathrm{C}\end{array}$ \\
\hline 84 & $\begin{array}{c}6.86(0.12) \\
\text { BCab }\end{array}$ & $\begin{array}{c}6.97(0.1) \\
\mathrm{Bb}\end{array}$ & $\begin{array}{c}6.69 \\
(0.15) \mathrm{Ca}\end{array}$ & $\begin{array}{c}7.48 \\
(0.31) \mathrm{Ca}\end{array}$ & $\begin{array}{c}7.19(0.26) \\
\mathrm{BCa}\end{array}$ & $\begin{array}{c}7.19(0.41) \\
\mathrm{CDa}\end{array}$ & $\begin{array}{c}6.78(0.1) \\
\mathrm{ABCa}\end{array}$ & $\begin{array}{c}7.62 \\
(0.26) \mathrm{Db}\end{array}$ & $\begin{array}{c}6.91 \\
(0.36) \mathrm{Ca}\end{array}$ & $\begin{array}{c}6.63 \\
(0.12) \mathrm{A}\end{array}$ & $\begin{array}{c}7.87 \\
(0.23) \mathrm{C}\end{array}$ \\
\hline 168 & $\begin{array}{c}6.63 \\
(0.04) \mathrm{Ba}\end{array}$ & $\begin{array}{c}6.97 \\
(0.09) \mathrm{Bb}\end{array}$ & $\begin{array}{c}6.74 \\
(0.12) \mathrm{Ca}\end{array}$ & $\begin{array}{c}7.47 \\
(0.17) \mathrm{Ca}\end{array}$ & $\begin{array}{c}7.27 \\
(0.24) \mathrm{Ca}\end{array}$ & $\begin{array}{c}6.71 \\
(0.55) \mathrm{Cb}\end{array}$ & $\begin{array}{c}6.91(0.08) \\
\mathrm{BCa}\end{array}$ & $\begin{array}{c}7.4(0.37) \\
\mathrm{BCDb}\end{array}$ & $\begin{array}{c}6.94 \\
(0.12) \mathrm{Ca}\end{array}$ & $\begin{array}{c}6.56 \\
(0.25) \mathrm{A}\end{array}$ & $\begin{array}{c}7.89 \\
(0.15) \mathrm{C}\end{array}$ \\
\hline
\end{tabular}

\section{$\mathrm{pH}$ changes}

$\mathrm{pH}$ changes of uncoated specimens are presented in Figure 3. The $\mathrm{pH}$ of dental materials differed in the first measurement ( $1 \mathrm{~h}$ time point) in the following order: $\mathrm{FIL}<\mathrm{FUJ}$ $<\mathrm{CN}<\mathrm{BF}(6.16,6.47,6.83$, and 7.26). Also, the values differed at the last measurement (168 days): FUJ $<$ FIL $<\mathrm{CN}<$ BF $(6.56,6.63,6.91$, and 7.45).

$\mathrm{pH}$ values in coated and uncoated specimens are presented in Table 3. $\mathrm{pH}$ values showed growth tendency over time

\section{Promjene $\mathrm{pH}$ vrijednosti}

Vrijednosti $\mathrm{pH}$ otopine kod restaurativnih materijala korištenih bez premaza prikazane su na slici 3. Vrijednosti $\mathrm{pH}$ među dentalnim materijalima razlikovale su se pri prvom mjerenju poslije jednoga sata prema sljedećem redoslijedu: FIL < FUJ < CN < BF (6,16, 6,47, 6,83 i 7,26). Vrijednosti su se također razlikovale pri zadnjem mjerenju nakon 168 dana: FUJ $<$ FIL $<\mathrm{CN}<\mathrm{BF}(6,56,6,63,6,91$ i 7,45$)$. 


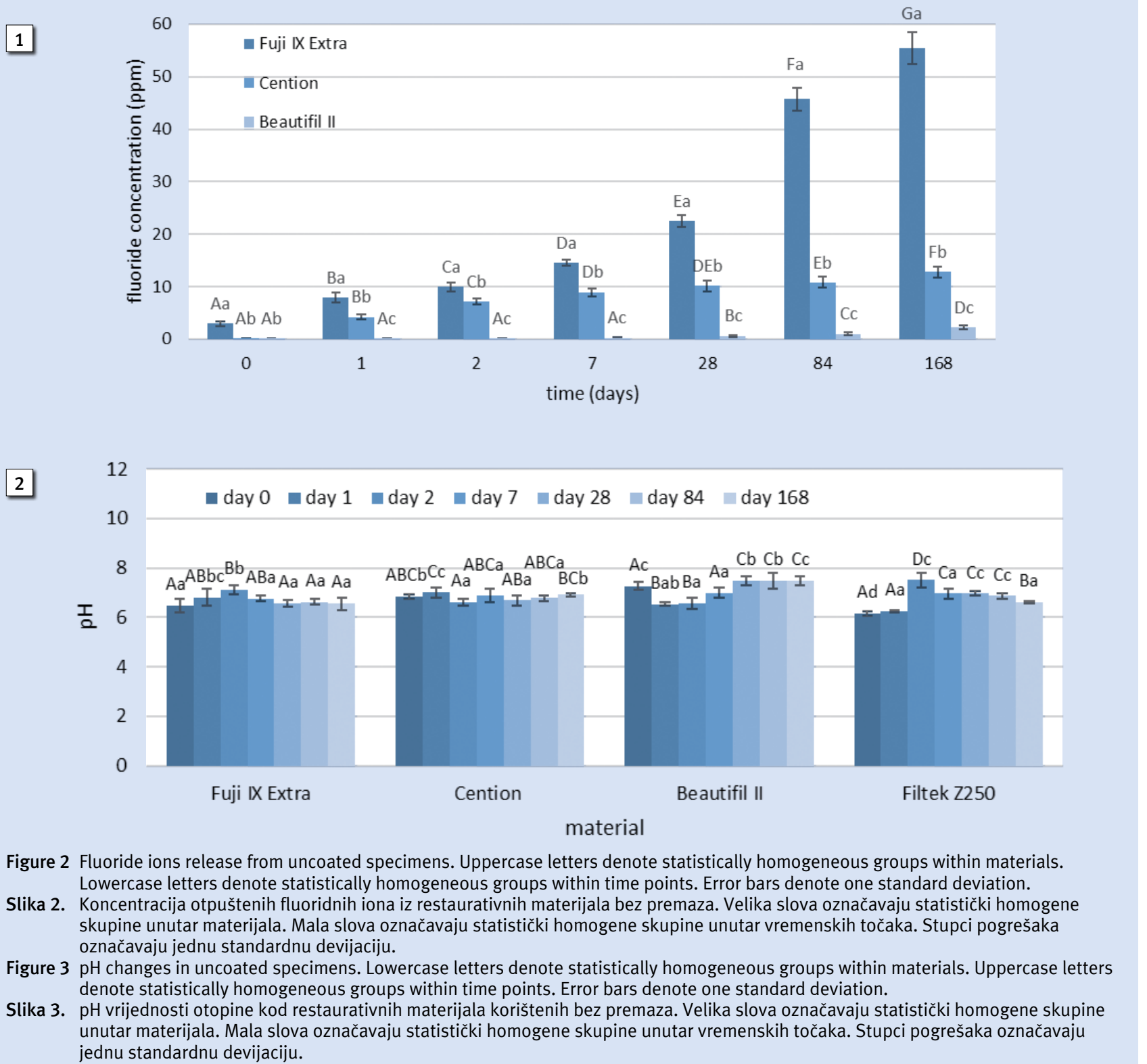

in all tested materials. FIL and $\mathrm{CN}$ showed higher $\mathrm{pH}$ values when coated with $\mathrm{CB}$ than the uncoated group. BF showed the highest values in the uncoated group. FUJ showed higher values when coated with FC. GB showed lower $\mathrm{pH}$ values in all groups after 1 hour and 24 hours. After 1 hour, the $\mathrm{pH}$ values among the materials increased in the following order: $\mathrm{FIL}<\mathrm{CN}<\mathrm{BF}(4.42,4.53$, and 4.75). After 24 hours, the $\mathrm{pH}$ values increased among the materials in the following order: $\mathrm{FIL}<\mathrm{BF}<\mathrm{CN}(5.39,5.67$, and 5.73).

\section{Discussion}

This study investigated fluoride release of four restorative materials and the effect of contemporary universal adhesive systems, and a coat on fluoride ions release. Also, for all coat-
Vrijednosti $\mathrm{pH}$ premazanih i nepremazanih uzoraka prikazane su u tablici 3. Vrijednosti pH pokazale su tendenciju rasta tijekom vremena u svim ispitivanim materijalima. FIL i $\mathrm{CN}$ imali su veće vrijednosti $\mathrm{pH}$ kada su bili premazani $\mathrm{CB}$ om u usporedbi sa skupinom bez premaza. BF je pokazao najviše vrijednosti u skupini bez premaza. FUJ je pokazao veće vrijednosti kada je korišten premaz FC. GB je pokazao niže $\mathrm{pH}$ vrijednosti u svim skupinama poslije jednoga sata i 24 sata. Nakon jednoga sata $\mathrm{pH}$ vrijednosti među materijalima povećavale su se prema sljedećem redoslijedu: $\mathrm{FIL}<\mathrm{CN}<\mathrm{BF}$ $(4,42,4,53$ i 4,75). Nakon 24 sata vrijednosti $\mathrm{pH}$ povećale su se među materijalima sljedećim redoslijedom: FIL $<$ BF < $\mathrm{CN}(5,39,5,67$ i 5,73$)$.

\section{Rasprava}

U ovoj studiji autori su istraživali otpuštanje fluoridnih iona iz četiriju restaurativnih materijala i učinak suvremenih univerzalnih dentinskih adhezijskih sustava i premaza 
ed and uncoated specimens, $\mathrm{pH}$ changes were evaluated. According to a statistically significant effect of the material type and resinous coating on fluoride release and $\mathrm{pH}$ changes, both null hypotheses were rejected.

All fluoride-releasing materials used in this study showed long-term fluoride release, as reported in several previous studies $(18,19)$. FUJ presented the highest cumulative values of released fluoride ions, followed by $\mathrm{CN}$ and BF. As expected, the conventional composite FIL did not release fluoride ions, except when its specimens were coated with the fluoride-releasing adhesive $\mathrm{CB}$.

GICs are characterized by the initial release of a large amount of fluoride ions called the burst effect which occurs within $24 \mathrm{~h}$ of cement setting time (20-22). According to Wiegand et al., this effect results from a reaction between glass particles and polyalkenoate acid (1).

Our study confirmed a similar burst effect in FUJ specimens, and also in the alkasite composite material CN. However, the burst effect was present only in uncoated FUJ and $\mathrm{CN}$ specimens. The observed burst effect found in $\mathrm{CN}$ could be a result of its composition. According to the respective manufacturer, this material comprises $78.4 \mathrm{wt} \%$ of the following inorganic fillers: barium aluminum silicate glass, ytterbium trifluoride, Isofiller (patented filler), calcium barium aluminum fluorosilicate glass, and a calcium fluorosilicate (alkaline) glass. Also, $24.6 \mathrm{wt} \%$ of the material is composed of alkaline (calcium fluorosilicate) glass filler, which is responsible for fluoride, hydroxide, and calcium ions release (14).

Our results are partially in contrast with those from a study of Gupta et al., which tested similar materials, Cention N (self- and light-cured) and a conventional GIC. Their results showed a time-dependent decrease in fluoride release from all tested materials, except for GIC in an acidic immersion medium. This difference between the released fluoride ions could be a result of different measuring time periods in the aforementioned study $(7,21$, and 28 days). However, their results of a GIC in neutral medium releasing significantly higher amounts of fluoride ions than Cention $\mathrm{N}$ corroborate our results of fluoride ions release in these materials (23).

Tiskaya et al. evaluated fluoride release, $\mathrm{pH}$ changes, and apatite formation of two bioactive composites (Cention N and Activa). Their cumulative values of fluoride ions release were below 8 ppm after 42 days, which is lower than the values obtained in our study (30.49 ppm after 28 days). This difference could be due to different specimen geometry and different immersion media. In our study, specimens were stored in deionized water while artificial saliva was used in the aforementioned study. Specimens immersed in artificial saliva tend to show a $17-25 \%$ lower fluoride release compared to specimens immersed in water $(24,25)$. This is explained by a lower diffusion gradient between the material and artificial saliva compared to the diffusion gradient between the material and deionized water. Also, artificial saliva may contain components that form a pellicle on the material surface and thereby interfere with ion release, decreasing it for about 15$20 \%(1,25-27)$. na otpuštanje fluoridnih iona. Također su se za sve premazane i nepremazane uzorke pratile promjene $\mathrm{pH}$ vrijednosti imerzijskog sredstva. Prema utvrđenom statistički značajnom učinku vrste materijala i premaza na otpuštanje fluoridnih iona i promjene $\mathrm{pH}$, sve nulte hipoteze su odbačene.

Svi materijali koji otpuštaju fluoridne ione korišteni u ovoj studiji pokazali su dugotrajno otpuštanje fluorida, kako je navedeno i u nekoliko ranijih studija $(18,19)$. Najviše kumulativne vrijednosti otpuštenih fluoridnih iona imali su uzorci FUJ-a, zatim slijede CN i BF. Očekivano, konvencionalni kompozit FIL nije otpuštao fluoridne ione, osim u skupini premazanoj dentinskim adhezijskim sustavom CB koji ima svojstvo otpuštanja fluoridnih iona.

Staklenoionomerne cemente karakterizira početno otpuštanje velike količine fluoridnih iona pod nazivom burst effect koji se pojavljuje unutar 24 sata od početka vezivanja cementa $(20$ - 22). Prema Wiegandu i suradnicima, navedeni učinak rezultat je reakcije između čestica stakla i polialkenoatne kiseline (1).

U ovom istraživanju potvrđen je burst effect kod FUJ uzoraka, a i u alkasitnom kompozitnom materijalu CN. No učinak se pojavio samo u uzorcima FUJ i CN pripremljenima bez premaza. Uočen efekt pronađen u $\mathrm{CN}-u$ mogao bi biti rezultat njegova sastava. Kako navodi proizvođač, taj materijal sadržava 78,4 \% težinskog udjela sljedećih anorganskih punila: barij-aluminijeva silikatnog stakla, iterbijeva trifluorida, Isofillera (patentirano punilo), kalcij-barij-aluminijeva fluorosilikatnog stakla i kalcijeva fluorosilikata (alkalno staklo). Također se $24,6 \%$ težinskoga udjela materijala sastoji od alkalnoga (kalcijeva fluorosilikatnog) staklenog punila odgovornog za otpuštanje fluoridnih, hidroksilnih i kalcijevih iona (14).

Rezultati u ovoj studiji djelomično su u suprotnosti $s$ onima iz studije Gupta i suradnika koji su testirali slične materijale, Cention N (kemijski polimerizirani i svjetlosno polimerizirani) i konvencionalni SIC. Njihovi su rezultati pokazali vremenski ovisno smanjenje otpuštanja fluoridnih iona iz svih ispitivanih materijala, osim SIC-a u kiselom imerzijskom mediju. Ta razlika između otpuštenih fluoridnih iona mogla bi biti rezultat različitih razdoblja mjerenja u spomenutoj studiji (7, 21 i 28 dana). No njihovi rezultati uzoraka SIC-a u neutralnom mediju koji otpuštaju znatno veće količine fluoridnih iona od Centiona $\mathrm{N}$, potvrđuju naše rezultate o otpuštanju fluoridnih iona u tim materijalima (23).

Tiskaya i suradnici proučavali su otpuštanje fluoridnih iona, promjene $\mathrm{pH}$ i stvaranje apatita dvaju bioaktivnih kompozita (Cention N i Activa). Njihove kumulativne vrijednosti otpuštanja fluoridnih iona bile su manje od 8 ppm nakon 42 dana, što je niže od vrijednosti dobivenih u našem istraživanju (30,49 ppm nakon 28 dana). Ta razlika može biti posljedica različite geometrije uzorka i različitih imerzijskih medija. U našem istraživanju uzorci su bili pohranjeni u deioniziranoj vodi, a u spomenutom istraživanju korištena je umjetna slina. Uzorci uronjeni u umjetnu slinu pokazuju od 17 do 25 $\%$ niže vrijednosti otpuštenih fluoridnih iona u usporedbi s uzorcima uronjenima u deioniziranu vodu $(24,25)$. Smatra se da je to rezultat nižeg gradijenta difuzije između materija- 
The giomer BF did not show the burst effect, which is in correspondence with the study of Yap et al. (28). The slower release of fluoride ions from BF can be attributed to its hydrophobic resinous matrix and a relatively low amount of pre-reacted glass ionomer fillers. Similar to the findings of our study, Mousavinasab et al. have also reported a higher release of fluoride ions from a GIC compared to a giomer. According to their study, the differences in fluoride ions release between those materials could be caused by a greater porosity of GIC, lack of glass ionomer matrix phase, and incorporated resin components in giomers (29).

In our study, the giomer showed the lowest cumulative fluoride release. According to a study by Colceriu Burtea et al., this finding can be explained by material characteristics where giomers include polyacrylic acid from PRG (pre-reacted glass) rather than amino acid modified polyalkenoic acid in the composition of the PRG. They also found that experimental giomers which contained hydrophilic and flexible polymer matrix based on UDMA showed higher cumulative fluoride ions release than giomers based on rigid and hydrophobic dimethacrylates (TEGDMA in BF) $(1,19,28,30)$.

The results of our study showed that the amount of released fluoride ions in all investigated materials was diminished in coated specimens, which is in line with previous studies $(7,11,12)$. Surprisingly, the fluoride-releasing adhesive system reduced the amount of leached fluoride ions.

In the present study, the materials coated with GB showed higher fluoride ions release than materials coated with the fluoride-releasing adhesive system CB. This could be explained by material composition. Water sorption depends on material hydrophilicity and can reduce polymer mechanical properties affecting its hygrothermal degradation and polymer hydrolysis that later forms water channels, surface erosions, and crazing that impact material permeability (31-34). High concentrations of acidic monomers contribute to hydrophilicity. GB contains $5-10 \%$ phosphoric acid ester monomers, while $\mathrm{CB}$ contains hydrophilic amide monomers $(35,36)$. Resin monomers with ester bonds are highly prone to hydrolysis in the presence of water, which could be one of the reasons for an increased fluoride ions release from materials coated with $\operatorname{GB}(37,38)$. Also, some studies found that resin polarity can act as a major determinant of water uptake. An increase in polarity results in higher water sorption. Polar functional groups include $\mathrm{OH}$-groups, carboxyl groups and phosphate groups, which tend to form hydrogen bonds with water. The water molecules that are „bound” by polar functional groups induce swelling and plasticization of the polymer network $(31,39-41)$. The GB adhesive system used in this study had dimethacrylate (10-20\%) and dimethacrylate components $(1-5 \%)$. Those components could partially explain an increased amount of released fluoride ions from materials coated with GB.

The hydrophilic resins used in universal adhesive systems are prone to limited monomer conversion due to phase separation which leads to degradation in an aqueous medium $(38,42)$. Oguri et al. showed that degree of conversion could depend on the functional monomer and photoinitiator system (43). Also, the lack of compatibility between hydropho- la i umjetne sline u usporedbi s gradijentom difuzije između materijala i deionizirane vode. Umjetna slina također može sadržavati komponente koje tvore pelikulu na površini materijala i tako ometaju otpuštanje iona, smanjujući ga za oko 15 do $20 \%(1,25-27)$.

Giomer BF nije pokazao burst effect, što je u skladu sa istraživanjem Yapa i suradnika (28). Sporije otpuštanje fluoridnih iona iz BF-a može se pripisati njegovoj hidrofobnoj smolastoj matrici i razmjerno maloj količini prethodno reagiranih staklenoionomernih čestica punila. Slično našem istraživanju, Mousavinasab i suradnici također su izvijestili o većem otpuštanju fluoridnih iona iz SIC-a u usporedbi $s$ giomerom. Prema njihovu istraživanju, razlike u otpuštanju fluoridnih iona između materijala mogle bi biti prouzročene većom poroznošću SIC-a, nedostatkom matrične faze i ugrađenim komponentama smole u giomere (29).

$\mathrm{U}$ našoj studiji giomer je pokazao najniže kumulativno otpuštanje fluoridnih iona, a prema studiji Colceriu Burtea i suradnika te se vrijednosti mogu objasniti karakteristikama materijala u kojima giomeri uključuju poliakrilnu kiselinu iz PRG-a, a ne modificiranu aminokiselinu polialkenoatne kiseline u sastavu PRG-a. Također su otkrili da su eksperimentalni giomeri koji su sadržavali hidrofilnu i fleksibilnu polimernu matricu na bazi UDMA-e pokazivali veće kumulativno otpuštanje fluoridnih iona od giomera na bazi krutih i hidrofobnih dimetakrilata (TEGDMA u BF-u) $(1,19,28,30)$.

Rezultati ovog istraživanja pokazali su da je količina otpuštenih fluoridnih iona u svim ispitivanim materijalima bila niža u premazanim uzorcima, što je u skladu s ranijim studijama $(7,11,12)$. Iznenađuje da je dentinski adhezijski sustav koji otpušta fluoridne ione smanjio količinu otpuštenih fluoridnih iona.

$\mathrm{U}$ ovom istraživanju su materijali premazani GB-om pokazali veće otpuštanje fluoridnih iona od onih premazanih adhezijskim sustavom CB koji ima svojstvo otpuštanja fluoridnih iona. Dobiveni rezultat mogao bi se objasniti sastavom materijala. Sorpcija vode ovisi o hidrofilnosti materijala i može smanjiti mehanička svojstva polimera tako što utječe na njegovu higrotermalnu razgradnju i hidrolizu polimera koja poslije stvara vodene kanale, površinske erozije i pukotine koje utječu na propusnost materijala $(31-34)$. Visoka koncentracija kiselih monomera pridonosi hidrofilnosti, GB sadržava od 5 do $10 \%$ monomera estera fosforne kiseline, a CB pak monomere hidrofilnih amida $(35,36)$.

Monomeri smole s esterskim vezama vrlo su skloni hidrolizi u prisutnosti vode, što bi mogao biti jedan od razloga za povećano otpuštanje fluoridnih iona iz materijala premazanih adhezijskim sustavom GB $(37,38)$. Također je u nekim istraživanjima otkriveno da polaritet smole može djelovati kao glavna odrednica sorpcije vode. Što je smola polarnija, to je veća sorpcija vode. Polarne funkcionalne skupine uključuju OH- skupine, karboksilne skupine i fosfatne skupine koje imaju tendenciju stvaranja vodikovih veza s vodom. Molekule vode koje su „vezane” polarnim funkcionalnim skupinama izazivaju bubrenje i plastificiranje polimerne mreže $(31,39$ 41). Dentinski adhezijski sustav GB korišten u ovoj studiji u svojem sastavu ima dimetakrilat $(10-20 \%)$ i dimetakrilatne komponente $(1-5 \%)$. Te bi komponente mogle djelomič- 
bic photoinitiator and hydrophilic monomers showed lower values of degree of conversion when compared with hydrophilic photoinitiator and monomers. A lower degree of conversion can affect adhesive permeability and lead to acidic monomer diffusion (44-46). CB scientific documentation declares the presence of hydrophobic photoinitiator camphorquinone and hydrophilic amide monomers which could explain lower $\mathrm{pH}$ values than $\mathrm{pH}$ values in uncoated specimens after 1 hour for BF and FIL, and after 24 hours for $\mathrm{CN}$ (35). A lower degree of conversion can also be speculated to have led to lower $\mathrm{pH}$ values for $\mathrm{GB}$ at time intervals 1 hour and 24 hours.

According to its respective manufacturer, $\mathrm{CN}$ shows a buffering ability by releasing acid-neutralizing hydroxide ions. Our results demonstrated small $\mathrm{pH}$ changes when $\mathrm{CN}$ was exposed to neutral medium, which can be compared with the studies of Gupta et al. and Tiskaya et al. $(23,24)$. Also, an interesting finding from our study was that the average $\mathrm{pH}$ level for $\mathrm{CN}$ was higher in the group that was coated with $\mathrm{CB}$ compared with the uncoated group. A similar result was present for FIL, but not for BF, and this could be due to increased reactivity when the acidic coat was applied.

FUJ also presented higher $\mathrm{pH}$ values when coated with FC. Given that uncoated FUJ specimens tended to decrease the $\mathrm{pH}$ value from neutral to acidic over time, the barrier formed in coated specimens showed a lack of that tendency.

GB showed lower $\mathrm{pH}$ levels than uncoated specimens and coated with CB. This can be related with a higher concentration of released fluoride ions when compared with materials coated with CB adhesive. The results of similar studies showed that the highest fluoride ions release was found in acidic medium (23, 47-49).

\section{Conclusions}

The amount of released fluoride ions varied among dental materials and depended on the use of adhesive systems and coatings. The glass ionomer Fuji IX Extra showed the highest values of released fluoride ions followed by the alkasite material Cention and the giomer Beautifil II. Both adhesive systems and the coat had a diminishing effect on released fluoride ions. $\mathrm{pH}$ values of the immersion medium differed among materials, treatments and time points. The amount of released fluoride ions showed a growth tendency over time in all tested materials. The lowest $\mathrm{pH}$ values were identified in all material specimens coated with G-aenial Bond. no objasniti povećanu količinu otpuštenih fluoridnih iona iz materijala premazanih GB-om.

Hidrofilne smole koje se koriste u univerzalnim dentinskim adhezijskim sustavima sklone su ograničenoj konverziji monomera zbog razdvajanja faza, što potiče razgradnju u vodenom mediju $(38,42)$. Oguri i suradnici pokazali su da stupanj konverzije može ovisiti o funkcionalnom monomeru i sustavu fotoinicijatora (43). Nedostatak kompatibilnosti između hidrofobnog fotoinicijatora i hidrofilnih monomera također je pokazao nižu vrijednost stupnja konverzije u usporedbi s hidrofilnim fotoinicijatorom i monomerima. Niži stupanj pretvorbe može utjecati na propusnost adhezijskog sustava i rezultirati difuzijom kiseloga monomera $(44-46)$. U znanstvenoj dokumentaciji o CB-u navodi se prisutnost hidrofobnog fotoinicijatora kamforkinona i hidrofilnih amidnih monomera koji bi mogli objasniti niže $\mathrm{pH}$ vrijednosti od $\mathrm{pH}$ vrijednosti na nepremazanim uzorcima nakon jednog sata za BF i FIL, te nakon 24 sata za CN (35). Također se može pretpostaviti da je niži stupanj konverzije doveo do nižih vrijednosti pH kod uzoraka premazanih GB-om u vremenskim razmacima od jednoga sata i 24 sata.

Prema proizvođaču, CN pokazuje pufersko svojstvo otpuštanjem hidroksidnih iona koji neutraliziraju kiselinu. $\mathrm{Na}$ ši rezultati pokazali su male promjene $\mathrm{pH}$ kada je $\mathrm{CN}$ bio izložen neutralnom mediju i mogu se usporediti sa studijama Gupta i suradnika te Tiskaya i suradnika $(23,24)$. Također je zanimljivo otkriće u našoj studiji bilo da je prosječna razina $\mathrm{pH}$ za CN bila viša u skupini premazanoj CB-om negoli u onoj nepremazanoj. Sličan rezultat dobiven je za FIL, ali ne i za BF, a to bi moglo biti zbog povećane reaktivnosti kada se nanese kiseli sloj.

FUJ je također pokazao veće $\mathrm{pH}$ vrijednosti kod uzoraka premazanih FC- om. S obzirom na to da su uzorci FUJ-a bez premaza $s$ vremenom smanjivali $\mathrm{pH}$ vrijednost $s$ neutralnog na kiseli, barijera nastala u premazanim uzorcima onemogućila je spomenutu pojavu.

$\mathrm{GB}$ je pokazao nižu razinu $\mathrm{pH}$ vrijednosti od nepremazanih uzoraka i uzoraka premazanih CB-om. Navedeni rezultat može se povezati s većom koncentracijom otpuštenih fluoridnih iona u usporedbi s materijalima premazanima $\mathrm{CB}$ adhezivom. U sličnim je istraživanjima istaknuto da se najveće otpuštanje fluoridnih iona događa u kiselom mediju (23, $47-49)$.

\section{Zaključak}

Količina otpuštenih fluoridnih iona varirala je među dentalnim materijalima i ovisila je o upotrebi dentinskih adhezijskih sustava i premaza. Stakleni ionomer Fuji IX Extra pokazao je najveće vrijednosti otpuštenih fluoridnih iona, a slijedili su ga alkasitni materijal Cention i giomer Beautifil II. Dentinski adhezijski sustavi i premaz umanjili su otpuštanje fluoridnih iona. Vrijednosti $\mathrm{pH}$ imerzijskog sredstva razlikovale su se između materijala, tretmana i vremenskih točaka. Količina otpuštenih fluoridnih iona pokazala je tendenciju rasta tijekom vremena u svim ispitivanim materijalima. Najniže $\mathrm{pH}$ vrijednosti utvrđene su u svim uzorcima materijala premazanima G-aenial Bondom. 


\section{Conflict of interest}

The authors report no conflict of interest

\section{Acknoweledgements}

This study was supported by the Croatian Science Foundation (Project IP-2019-04-6183, Biomimetic Intelligent Composite Materials). Head: professor Zrinka Tarle. The authors would like to thank Ms. Ankica Tečić for technical assistance. The authors are also grateful to Ivoclar Vivadent (Schaan, Liechtenstein) for donating alkasite material.

\section{Author's contribution}

K.K. - research, data collection, formal analysis, interpretation, visualization, writing - original draft, approval of the final version of the article for publication; M.P. - concept and design, formal analysis, statistical analysis, interpretation, writing - critical review and editing, approval of the final version of the article for publication; K.P. - concept and design, supervision, interpretation, writing - critical review and editing, approval of the final version of the article for publication; I.S. - concept and design, supervision, interpretation, writing - critical review and editing, approval of the final version of the article for publication; Z.T. - supervision, resources, writing - critical review and editing, approval of the final version of the article for publication

\section{Sukob interesa}

Autori nisu bili u sukobu interesa.

\section{Zahvala}

Ovu studiju poduprla je Hrvatska zaklada za znanost (Projekt IP-2019-04-6183, Biomimetički inteligentni kompozitni materijali). Voditelj: prof. dr. sc. Zrinka Tarle. Autori žele zahvaliti Ankici Tečić na tehničkoj pomoći. Autori su također zahvalni tvrtki Ivoclar Vivadent (Schaan, Liechtenstein) na doniranju alkasitnog materijala.

\section{Doprinos autora}

K. K. - istraživanje, prikupljanje podataka, formalna analiza, interpretacija, vizualizacija, pisanje - originalni nacrt, odobravanje krajnje verzije članka za objavljivanje; $\mathbf{M}$. P. - koncept i dizajn, formalna analiza, statistička analiza, interpretacija, pisanje - kritički pregled i uređivanje, odobravanje krajnje verzije članka za objavljivanje; K. P. - koncept i dizajn, supervizija, interpretacija, pisanje - kritički pregled i uređivanje, odobravanje krajnje verzije članka za objavljivanje; I. S. - koncept i dizajn, supervizija, interpretacija, pisanje - kritički pregled i uređivanje, odobravanje krajnje verzije članka za objavljivanje; Z. T. - supervizija, resursi, pisanje - kritički pregled i uređivanje, odobravanje krajnje verzije članka za objavljivanje

\section{Sažetak}

Svrha rada: Cilj istraživanja bio je utvrditi učinak dvaju dentinsko adhezijskih sustava i staklenoionomerne smole na količinu otpuštenih fluoridnih iona i promjenu pH tijekom 168 dana. Materijali i metode: $U$ istraživanju su korištena četiri restaurativna materijala: giomer Beautifil II, alkasitni kompozitni materijal Cention, konvencionalni kompozit Filtek Z 250 i konvencionalni staklenoionomerni cement Fuji IX Extra. Svjetlosno polimerizirani kompozitni uzorci premazani su G-aenial Bondom i adhezivom Clearfil Universal Bond Quick. Na uzorke sa staklenoionomernim cementom nanesen je premaz GC Fuji Coat LC. Uzorci bez premaza korišteni su kao referencije. Mjerenja količine otpuštenih fluoridnih iona i pH vrijednosti provedena su u sljedećim vremenskim intervalima: 1 sat, 24 sata, 2 dana, 7 dana, 28 dana, 84 dana i 168 dana. Rezultati: Kumulativne količine otpuštenih fluoridnih iona poslije 168 dana povećale su se na nepremazanim uzorcima sljedećim redoslijedom: Filtek Z $250<$ Beautifil II < Cention < Fuji IX Extra. Kompoziti premazani Clearfil Universal Bond Quickom otpuštali su manju količinu fluoridnih iona od nepremazanih uzoraka, a kumulativne vrijednosti dosegnute nakon 168 dana povećavale su se sljedećim redoslijedom: Filtek Z $250<$ Beautifil II < Cention. Kompoziti premazani Gaenial Bondom također su otpuštali manje količine fluoridnih iona u usporedbi s nepremazanim uzorcima - kumulativne vrijednosti povećavale su se sljedećim redoslijedom: Filtek Z 250 < Beautifil II < Cention. Kompoziti premazani G-aenial Bondom u svim su skupinama pokazivali pH vrijednosti u kiselom rasponu $(4,4-5,7)$ u intervalima od jednoga i 24 sata. Zaključak: Količina otpuštenih fluoridnih iona varirala je među ispitivanim restaurativnim materijalima i ovisila je o upotrebi dentinskog adhezijskog sustava i premaza. Vrijednosti pH varirale su između materijala, tretmana i vremenskih intervala.
Zaprimljen: 14. rujna 2020.

Prihvaćen: 1. prosinca 2020.

Adresa za dopisivanje

Matej Par

Sveučilište u Zagrebu

Zavod za endodonciju i restaurativnu dentalnu medicinu

Gundulićeva 5,

10000 Zagreb

mpar@sfzg.hr

\section{Ključne riječi}

stomatološki cementi; fluoridi; koncentracija vodikovih iona; oslobađanje lijekova

\section{References}

1. Wiegand A, Buchalla W, Attin T. Review on fluoride-releasing restorative materials--fluoride release and uptake characteristics, antibacterial activity and influence on caries formation. Dent Mater. 2007 Mar;23(3):343-62.

2. Padala RG, Peddu R, Nuvusetty B, Mallavarapu K, Banswada $S R$, Mood TN. Effect of Fluoride-releasing Elastomers on Mutans Streptococci in Dental Plaque: An In Vivo Study. Contemp Dent Pract. 2019 Sep 1;20(9):1061-1066.

3. Shashibhushan KK, Basappa N, Subba Reddy VV. Comparison of antibacterial activity of three fluorides- and zinc-releasing commercial glass ionomer cements on strains of mutans streptococci: an in vitro study. J Indian Soc Pedod Prev Dent. 2008;26 Suppl 2:S56-61.

4. Ferreira L, Pedrini D, Okamoto AC, Jardim Júnior EG, Henriques TA, Cannon M, et al. Biochemical and microbiological characteristics of in situ biofilm formed on materials containing fluoride or amorphous calcium phosphate. Am J Dent. 2013 Aug;26(4):207-13.

5. Kumari PD, Khijmatgar S, Chowdhury A, Lynch E, Chowdhury CR. Factors influencing fluoride release in atraumatic restorative treatment (ART) materials: A review. J Oral Biol Craniofac Res. Oct-Dec 2019;9(4):315-320.

6. Jingarwar MM, Pathak A, Bajwa NK, Sidhu HS. Quantitative as sessment of fluoride release and recharge ability of different restorative materials in different media: an in vitro study. J Clin Diagn Res. 2014 Dec;8(12):ZC31-4.

7. Mazzaoui SA, Burrow MF, Tyas MJ. Fluoride release from glass ionomer cements and resin composites coated with a dentin adhesive. Dent Mater. 2000;16(3):166-71.

8. Nigam AG, Jaiswal JN, Murthy RC, Pandey RK. Estimation of fluoride release from various dental materials in different media-an in vitro study. Int J Clin Pediatr Dent. 2009 Jan;2(1):1-8. 
9. Vermeersch G, Leloup G, Vreven J. Fluoride release from glassionomer cements, compomers and resin composites. J Oral Rehabil. 2001 Jan;28(1):26-32.

10. Cabral MF, Martinho RL, Guedes-Neto MV, Rebelo MA, Pontes DG, Cohen-Carneiro F. Do conventional glass ionomer cements release more fluoride than resin-modified glass ionomer cements? Restor Dent Endod. 2015 Aug;40(3):209-15.

11. Vercruysse CW, De Maeyer EA, Verbeeck RM. Fluoride release of polyacid-modified composite resins with and without bonding agents. Dent Mater. 2001;17(4):354-8.

12. Miranda LA, Weidlich P, Samuel SM, Maltz M. Fluoride release from restorative materials coated with an adhesive. Braz Dent J. 2002;13(1):39-43.

13. Brzović-Rajić V, Miletić I, Gurgan S, Peroš K, Verzak Ž, IvaniševićMalčić A. Fluoride Release from Glass Ionomer with Nano Filled Coat and Varnish. Acta Stomatol Croat. 2018;52(4):307-13.

14. MeSH Browser [database on the Internet] Ivoclar Vivadet. Schaan:Ivoclar Vivadent AG; 2018. Cention N Scientific Documentation; 2016 [cited 2019 Sept 3]; [about 58 p.]. Available from: http://www.ivoclarvivadent.in/en-in/p/all/cention-n

15. Par M, Attin T, Tarle Z, Tauböck TT. A New Customized Bioactive Glass Filler to Functionalize Resin Composites: Acid-Neutralizing Capability, Degree of Conversion, and Apatite Precipitation. J Clin Med. 2020 Apr 19;9(4):1173.

16. Spajic J, Par M, Milat O, Demoli N, Bjelovucic R, Prskalo K. Effects of Curing Modes on the Microhardness of Resin-modified Glass Ionomer Cements. Acta Stomatol Croat. 2019;53(1):37-46.

17. Spajić J, Prskalo K, Šariri K, Par M, Pandurić V, Demoli N. Dimensional Changes of Glass Ionomers and a Giomer during the Setting Time. Acta Stomatol Croat. 2018;52(4):298-306.

18. Naoum S, Martin E, Ellakwa A. Long-term fluoride exchanges at restoration surfaces and effects on surface mechanical properties. ISRN Dent. 2013 Aug 19;2013:579039.

19. Colceriu Burtea L, Prejmerean C, Prodan D. New Pre-reacted Glass Containing Dental Composites (giomers) with Improved Fluoride Release and Biocompatibility. Materials (Basel). 2019 Dec 3;12(23):4021.

20. Kucukyilmaz E, Savas S, Kavrik F, Yasa B, Botsali MS. Fluoride release/recharging ability and bond strength of glass ionomer cements to sound and caries-affected dentin. Niger J Clin Pract. 2017;20(2):226-234.

21. Neelakantan P, John S, Anand S, Sureshbabu N, Subbarao C. Flu oride release from a new glass-ionomer cement. Oper Dent. JanFeb 2011;36(1):80-5.

22. Attar N, Onen A. Fluoride release and uptake characteristics of aesthetic restorative materials. J Oral Rehabil. 2002 Aug;29(8):791-8.

23. Gupta N, Jaiswal S, Nikhil V, Gupta S, Jha P, Bansal P. Comparison of fluoride ion release and alkalizing potential of a new bulk-fill alkasite. J Conserv Dent. 2019;22(3):296-99.

24. Tiskaya M, Al-Eesa NA, Wong FSL, Hill RG. Characterization of the bioactivity of two commercial composites. Dent Mater. 2019 Dec;35(12):1757-1768.

25. Bell A, Creanor SL, Foye RH, Saunders WP. The effect of saliva on fluoride release by a glass-ionomer filling material. J Oral Rehabil. 1999 May;26(5):407-12

26. Levallois B, Fovet Y, Lapeyre L, Gal JY. In vitro fluoride release from restorative materials in water versus artificial saliva medium (SAGF). Dent Mater. 1998 Nov;14(6):441-7.

27. Arends J, Dijkman GE, Dijkman AG. Review of fluoride release and secondary caries reduction by fluoridating composites. Adv Dent Res. 1995;9:367-76.

28. Yap AU, Tham SY, Zhu LY, Lee HK. Short-term fluoride release from various aesthetic restorative materials. Oper Dent. May-Jun 2002;27(3):259-65.

29. Mousavinasab SM, Meyers I. Fluoride release by glass ionomer cements, compomer and giomer. Dent Res J (Isfahan). 2009;6(2):75-81.

30. Rusnac ME, Gasparik C, Irimie AI, Grecu AG, Mesaroş AŞ, Dudea D. Giomers in dentistry - at the boundary between dental composites and glass-ionomers. Med Pharm Rep. 2019 Apr;92(2):123-128.
31. Ito S, Hashimoto M, Wadgaonkar B, Svizero N, Carvalho RM, Yiu C et al. Effects of resin hydrophilicity on water sorption and changes in modulus of elasticity. Biomaterials. 2005 Nov;26(33):644959.

32. Tay FR, Pashley DH, Suh B, Carvalho R, Miller M. Single-step, selfetch adhesives behave as permeable membranes after polymerization. Part I. Bond strength and morphologic evidence. Am J Dent. 2004 Aug;17(4):271-8.

33. Feitosa VP, Leme AA, Sauro S, Correr-Sobrinho L, Watson TF, Sinhoreti MA, Correr AB. Hydrolytic degradation of the resin-dentine interface induced by the simulated pulpal pressure, direct and indirect water ageing. J Dent. 2012 Dec;40(12):1134-43.

34. Yiu CK, King NM, Pashley DH, Suh BI, Carvalho RM, Carrilho MR, Tay FR. Effect of resin hydrophilicity and water storage on resin strength. Biomaterials. 2004 Nov;25(26):5789-96.

35. MeSH Browser [database on the Internet] Kuraray. Okayama: Kuraray Noritake Dental Inc; 2017. CLEARFIL UNIVERSAL BOND Quick: SDS USA; 2017 [cited 2020 May 3]; [about 9 p.]. Available from: https://kuraraydental.com/wp-content/uploads/sds/chairside/ usa/clearfil-universal-bond-quick-sds-usa.pdf.

36. MeSH Browser [database on the Internet] GC. Alsip: GC America Inc; 2015. Safety data sheet Gaenial Bond: 2015 [cited 2020 May 3]; [about 11 p.]. Available from: https://www.gcamerica.com/downloads/SDS_US/SDS_G-aenial\%20Bond.pdf.

37. Santerre JP, Shajii L, Leung BW. Relation of dental composite formulations to their degradation and the release of hydrolyzed polymeric-resin-derived products. Crit Rev Oral Biol Med. 2001;12:136-51.

38. Frassetto A, Breschi L, Turco G, Marchesi G, Di Lenarda R, Tay FR, et al. Mechanisms of degradation of the hybrid layer in adhesive dentistry and therapeutic agents to improve bond durability--A literature review. Dent Mater. 2016;32(2):41-53.

39. Tjäderhane L, Larjava H, Sorsa T, Uitto VJ, Larmas M, Salo T. The activation and function of host matrix metalloproteinases in dentin matrix breakdown in caries lesions. J Dent Res. 1998 Aug;77(8):1622-9.

40. Unemori M, Matsuya Y, Matsuya S, Akashi A, Akamine A. Water absorption of poly (methyl methacrylate) containing 4-methacryloxyethyl trimellitic anhydride. Biomaterials. 2003 Apr;24(8):1381-7.31.

41. Malacarne J, Carvalho RM, de Goes MF, Svizero N, Pashley DH, Tay FR, et al. Water sorption/solubility of dental adhesive resins. Dent Mater. 2006 Oct;22(10):973-80.

42. Spencer $P$, Wang Y. Adhesive phase separation at the dentin interface under wet bonding conditions. J Biomed Mater Res. 2002 Dec 5;62(3):447-56.

43. Oguri M, Yoshida Y, Yoshihara K. Effects of functional monomers and photo-initiators on the degree of conversion of a dental adhesive. Acta Biomater. 2012 May;8(5):1928-34

44. Ye Q, Park J, Topp E, Spencer P. Effect of photoinitiators on the in vitro performance of a dentin adhesive exposed to simulated oral environment. Dent Mater. 2009 Apr;25(4):452-8.

45. Wang Y, Spencer P, Yao X, Ye Q. Effect of coinitiator and water on the photoreactivity and photopolymerization of HEMA/camphoquinone-based reactant mixtures. J Biomed Mater Res A. 2006;78(4):721-8

46. Cadenaro M, Antoniolli F, Sauro S. Degree of conversion and permeability of dental adhesives. Eur J Oral Sci. 2005 Dec;113(6):52530 .

47. Karantakis $P$, Helvatjoglou-Antoniades $M$, Theodoridou-Pahini S, Papadogiannis Y. Fluoride release from three glass ionomers, a compomer, and a composite resin in water, artificial saliva, and lactic acid. Oper Dent. Jan-Feb 2000;25(1):20-5.

48. Carey CM, Spencer M, Gove RJ, Eichmiller FC. Fluoride release from a resin-modified glass-ionomer cement in a continuous-flow system. Effect of pH. J Dent Res. 2003 Oct;82(10):829-32.

49. Hayacibara MF, Ambrozano GM, Cury JA. Simultaneous release of fluoride and aluminum from dental materials in various immersion media. Oper Dent. Jan-Feb 2004;29(1):16-22. 